\title{
Pesquisas acadêmicas sobre biodiesel no Brasil: uma análise dos grupos do Conselho Nacional de Desenvolvimento Científico e Tecnológico (CNPq)
}

\author{
Academic research in biodiesel in Brazil: an analysis of groups of the National \\ Council for Scientific and Technological Development (CNPq)
}

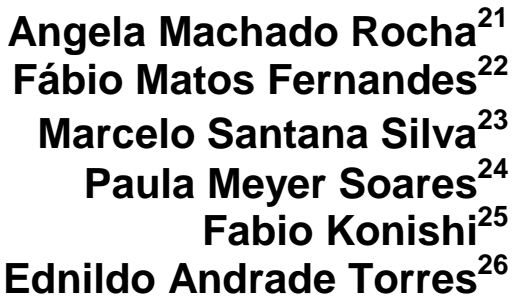

Artigo recebido para publicação em Mar./2014 e aceito para publicação em Maio/2014.

\section{RESUMO}

Preocupações com a segurança energética e mudanças climáticas têm incentivado muitos países a investimentos em energias renováveis. O Brasil possui uma longa e larga experiência na produção de biocombustíveis, sendo hoje líder de produção de etanol de cana-de-açúcar no mundo. Em 2004, o Programa Nacional de Produção e Uso do Biodiesel (PNPB) foi lançado, introduzindo o biodiesel em sua matriz energética em 2005. Neste contexto, buscando obter um mapeamento a cerca de indicadores científicos e tecnológicos sobre o biodiesel no Brasil, o presente trabalho abordou a temática do biodiesel como cerne, tendo desenvolvido um estudo centrado em uma metodologia, que contemplou a avaliação de indicadores estratificados por cada uma das 05 (cinco) regiões geográficas do país, considerando para isso: (i) número de pessoal; e, (ii) número de grupos e linhas de pesquisa formados. A pesquisa adota procedimentos descritivos, qualitativos e exploratórios, incluindo investigação bibliográfica e uma prospecção dos censos disponibilizados no Diretório dos Grupos e Linhas de Pesquisa cadastrados no Conselho Nacional de Desenvolvimento Científico e Tecnológico (CNPq) até 2013. Observou-se como principais resultados, que ao contrário dos países desenvolvidos, a pesquisa científica e tecnológica no Brasil no tocante ao biodisel se concentra nas Universidades, sendo ainda incipiente para interações com o setor produtivo, sugerindo que a expressiva produção de biodiesel ainda não seja indutor fundamental para o setor de PD\&l em biocombustíveis no Brasil.

Palavras-chaves: Biodiesel. Indicadores científicos. Brasil. Conselho Nacional de Desenvolvimento Científico e Tecnológico.

\section{ABSTRACT}

Concerns about energy security and climate change have encouraged many countries to investments in renewable energy. Brazil has a long and wide experience in the production of biofuels, being

${ }^{21}$ Doutora em Energia e Ambiente e Engenheira Química. Prof ${ }^{a}$ Adjunta da Universidade Federal da Bahia (UFBA). E-mail: anmach@gmail.com

${ }^{22}$ Mestre em Gestão e Tecnologia Industrial e Adminitsrador. Professor Assistente da Universidade Estadual da Bahia (UNEB).E-mail: fabfernandes@uneb.br

${ }^{23}$ Doutorando em Energia e Ambiente (CIENAM/UFBA), Mestre em Energia e Economista. Professor do Instituto Federal da Bahia (IFBA): E-mail: marcelosilva@ifba.edu.br

${ }^{24}$ Doutora em Economia e Economista. Professora da Universidade de Brasília (UnB). E-mail: paulameyer@unb.br

25 Mestre em Administração e Administrador. Professor da FATEC-SP. E-mail: profkonishi@uol.com.br

${ }^{26}$ Doutor em Engenharia Mecânica e Engenheiro Mecânico. Professor Associado da Universidade Federal da Bahia (UFBA). Coordenador do Centro Interdisciplinar de Energia e Ambiente (CIENAM).E-mail: ednildo@ufba.br 
nowadays the leader in the production of ethanol from sugar cane worldwide. In 2004, the National Program for Production and Use of Biodiesel (NPPB) was launched, introducing biodiesel in Brazilian energy matrix in 2005. In this context, seeking to obtain a mapping about science and technology indicators on biodiesel in Brazil, the present study addressed the issue of biodiesel as a core, having developed a study focused on a methodology, which included the review of indicators stratified by each of the five (05) geographical regions in Brazil, considering for that: (i) number of researchers; and, (ii) number of research groups and lines formed. It adopts descriptive, qualitative and exploratory procedures, including literature search and a survey of censuses available in the Directory of Research Themes Groups and registered with the National Council for Scientific and Technological Development (CNPq) until 2013. It was observed as the main results, that in contrast to developed countries, scientific and technological research in Brazil regarding the biodiesel focuses on Universities, being incipient to interactions with the Brazilian productive sector, suggesting that the significant national production of biodiesel is still not critical inducer for the Brazilian sector RD\&I in biofuels.

Keywords: Biodiesel. Scientific indicators. Brazil. National Council for Scientific and Technological Development.

\section{INTRODUÇÃO}

Atualmente, estamos vivendo uma grande revolução no âmbito tecnológico, sem nos dar conta e sem conhecer a totalidade das tecnologias que nos rodeiam. Mudanças tecnológicas se apresentam diariamente em todos os setores de conhecimento, e com elas, carreia-se a necessidade crescente de atualização a cerca da existência e disponibilidade de novas tecnologias, cuja incorporação no cotidiano de uma sociedade propicia a possibilidade de modernização, de maior desenvolvimento tecnológico, industrial e econômico para a nação.

A iniciativa de adotar tais tecnologias novas no cotidiano permite à criação de pontos referenciais distintos por meio da implementação de melhores processos, ferramentas mais adequados e acessórios sob medida no cotidiano da população, propiciando, assim, maior economia de esforços e divisas, ao mesmo tempo em que se assegura maior desenvolvimento e inovação para a sociedade.

Sob esta perspectiva de tecnologia voltada à sociedade é que o presente trabalho se desenvolve, apresentando objetivamente um estudo a respeito de indicadores científicos e tecnológicos sobre o biodiesel no Brasil, tema que abrange uma ampla gama de questões nas áreas de ciência e tecnologia, pesquisa, desenvolvimetno e inovação (PD\&l), empreendedorismo e dinâmica empresarial.

O biodiesel é um combustível biodegradavel e não tóxico ao meio ambiente, processado a partir de biomateriais ricos em gorduras e oleos, por exemplo, óleos vegetais (óleos de soja, mamona, macaúna, etc.), ou ainda, gordura animal (sebos), e que se equivalente ao óleo diesel, usado para abastecer motores de trens, grandes caminhoes e navios no mundo (KNOTHE; GESPEN; KRAHL, 2006). 
A química básica envolvida na produção do biodiesel é a troca catalítica de ésteres naturais, principalmente glicerídeos, com os radicais de um álcool primário. Durante esse processo conhecido como transesterificação, uma gordura ou óleo é reagido com um álcool primário (tal como metanol ou etanol) na presença de uma substância chamada de catalisador, que efetua a troca de ésteres naturais, tal como glicerídeo com o álcool primário para produzir glicerol e metil ésteres de ácido graxo, este ultimo do qual forma o biodiesel (KNOTHE; GESPEN; KRAHL, 2006).

A escassez aguda de petróleo e as oscilações constantes no preço final do barril têm alimentado o interesse mundial em combustiveis alternativos menos poluentes, tais como o biodiesel. Assim, alguns estudos reportam os esforços de uma extensa pesquisa tecnológica no Brasil (PINTO, 2005; ROCHA et al., 2013) e no mundo (ARANSIOLA et al., 2014).

Neste contexto, no presente trabalho foi desenvolvido um estudo centrado na apresentação de indicadores científicos e tecnológicos sobre o biodiesel no Brasil, para isso, tais indicadores foram estratificados por cada uma das 05 (cinco) regiões geográficas do país, empregando como base, os dados disponibilizados no Diretório dos Grupos de Pesquisa cadastrados no Conselho Nacional de Desenvolvimento Científico e Tecnológico (CNPq), adotando-se em adição, procedimentos descritivos, qualitativos e exploratórios, que incluíram a investigação bibliográfica e uma análise documental dos principais indicadores científicos e tecnológicos disponíveis para extração no Diretório dos Grupos de Pesquisa (DGP/CNPq), como mostrado na Figura 1 (INSTITUTO BRASILEIRO DE GEOGRAFIA E ESTATÍSTICA, 2013). 
EPIBGE

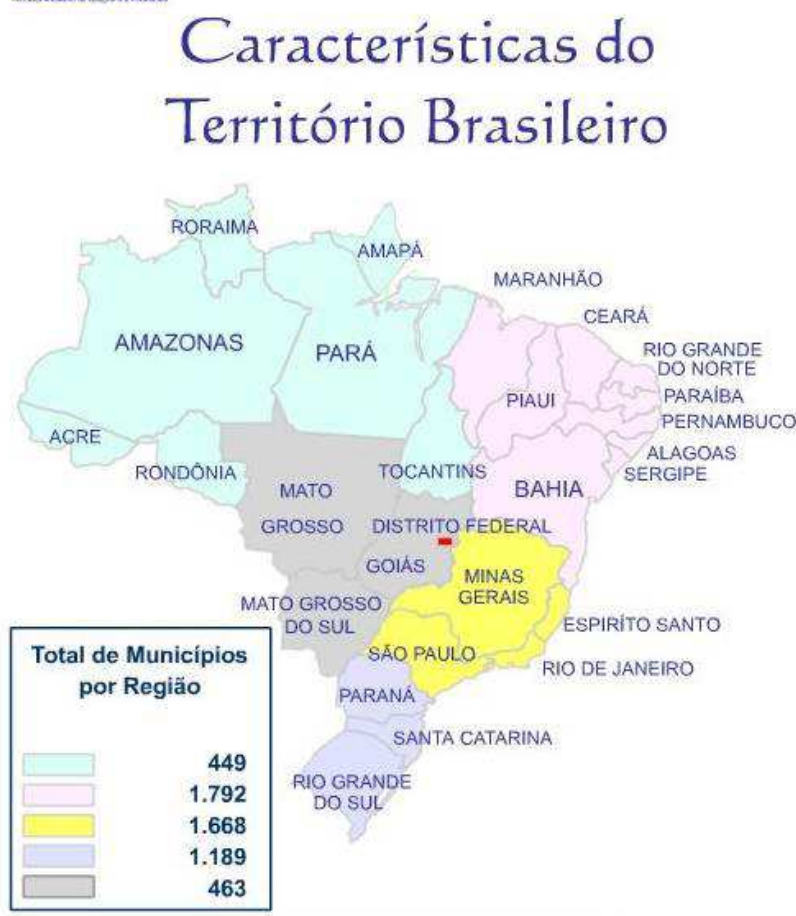

República Federativa do BRASIL

Sigla: $\mathbf{B R}$

Capital Federal: Brasilia

População - (1996): 157.070.163 hab.

Homens: 77.447 .541

Mulheres: 79.632.032

Área (2002): $8.514 .876,599 \mathrm{Km}^{2}$

Densidade Populacional - 1996: $18,38 \mathrm{hab} / \mathrm{Km}^{2}$

Gentílico: Brasileiro

Número de municípios existentes - 2001: 5.561

Clima:

Equatorial

Tropical (Zona Equatorial)

Tropical (Nordeste Oriental)

Tropical (Brasil Central)

Temperado

Ponto mais alto:

Topônimo: Pico da Neblina

Localização: Serra Imeri UF: Amazonas

Altitude : $3.014,1 \mathrm{~m}$

Pontos extremos:

Norte: Nascente do rio Ailă no monte Caburaí,

Roraima, fronteira com a Guiana.

Sul: Uma das curvas do arroio Chui, Rio Grande

do Sul, fronteira com o Uruguai.

Leste: Ponta do Seixas, Paraiba

Oeste: Nascentes do rio Moa, na serra de Contamana ou do Divisor, Acre, fronteira com o Peru.

Localização geográfica: Pontos Extremos

Latitude: entre $+5^{\circ} 16^{\prime} 20^{\prime \prime}$ e $-33^{\circ} 44^{\prime} 32^{\prime \prime}$

Longitude:entre $-34^{\circ} 47^{\prime} 30^{\prime \prime}$ e $-73^{\circ} 59^{\prime} 32^{\prime \prime}$

Fonte: Instituto Brasileiro de Geografia e Estatística (2013).

\section{BREVE PANORAMA DO BIODIESEL NO CONTEXTO MUNDIAL E BRASILEIRO}

No mundo, a história do biodiesel data de 1895, quando Rudolf Diesel e Henry Ford descobriram no processamento de óleos vegetais um caminho para o desenvolvimento industrial pela produção de combustível diesel alternativo ao diesel do petróleo (PACHECO, 2006). Assim, embora as pesquisas sobre biodiesel desenvolvidas por Diesel e Ford tenham se iniciado ao fim do século 19 apenas na década de 30 na Bélgica, as pesquisas sobre o biocombustível culminaramu com um primeiro pedido de patente belga - BE422,877: "Procedure for the transformation of vegetable oils for their uses as fuels"; realizado pelo senhor George Chavanne, da Universidade de Bruxelas. A referida patente descreve a alcoólise de óleos vegetais utilizando etanol (CHAVANNE, 1937). Na sequência, nos Estados Unidos, outras tecnologias para produção de biodiesel foram desenvolvidas e patenteadas, como por exemplo, modificações no processo para poder usar óleos de alta acidez (KEIM, 1945). 
Já no Brasil, a ideia do uso do biodiesel também não é nova e pode ser cronologicamente remontada como se segue no Quadro 1:

\begin{tabular}{|c|c|}
\hline DÉCADA & OCORRÊNCIA \\
\hline 1920 & $\begin{array}{l}\text { - O Instituto Nacional de Tecnologia - INT já estudava e testava } \\
\text { combustíveis alternativos e renováveis; }\end{array}$ \\
\hline 1960 & $\begin{array}{l}\text { - As Indústrias Matarazzo obtiveram ésteres a partir de óleo de } \\
\text { café por lavagem do grão, com álcool da cana de açúcar; }\end{array}$ \\
\hline 1970 & $\begin{array}{l}\text { - O Instituto Nacional de Tecnologia - INT, juntamente com o } \\
\text { Instituto de Pesquisas Tecnológicas - IPT e da Comissão } \\
\text { Executiva do Plano da Lavoura Cacaueira - CEPLAC } \\
\text { desenvolveram projetos de óleos vegetais como combustíveis, } \\
\text { com destaque para o DENDIESEL, produzido a partir do óleo de } \\
\text { dendê por meio do Projeto "Levantamento das Necessidades } \\
\text { Atuais e Futuras da Substituição de Matérias Primas e Insumos } \\
\text { Básicos de origem fóssil (petróleo e carvão mineral) por } \\
\text { produtos Naturais Renováveis" implementado no interior da } \\
\text { Bahia; }\end{array}$ \\
\hline
\end{tabular}

- A Universidade Federal do Ceará - UFC - desenvolveu pesquisas tendo a frente o pesquisador Expedito Parente com o intuito de encontrar fontes alternativas de energia. As experiências acabaram por revelar um novo combustível originário de óleos vegetais e com propriedades semelhantes ao óleo diesel convencional: o biodiesel.

- A UFCE também desenvolveu o querosene vegetal de aviação para o Ministério da Aeronáutica. Após os testes em aviões a jato, o combustível foi homologado pelo Centro Técnico Aeroespacial.

- Depósito do primeiro pedido de patente de biodiesel no Brasil Dr. Expedito José de Sá Parente (Fortaleza-CE) - PI 80043585 ;

$1980-0$ Governo Federal, em 1983, motivado pela alta nos preços de petróleo, lançou o Programa de Óleos Vegetais - OVEG, no qual foi testada a utilização de biodiesel e misturas combustíveis em veículos que percorreram mais de 1 milhão de quilômetros;

- Em 1988, teve início a produção em escala industrial de biodiesel na Áustria e na França; em 1988, também foi registrado o uso da palavra "Biodiesel" na literatura, de acordo com artigo de WANG R. "Development of Biodiesel Fuel", Taiyangneng Xuebao 9:434-436(1988), China;

- EUA aprovam biodiesel como combustível alternativo (1997);

- Setores no Brasil retomam os projetos para o uso do biodiesel. A Universidade Federal do Paraná testou tecnologias para a

1990 produção de ésteres de óleo de soja, visando a sua mistura ao diesel. Assim, de janeiro a março de 1998, sob a coordenação do Instituto de Tecnologia do Paraná-TECPAR, foram realizados em Curitiba experimentos de campo, com o uso monitorado de biodiesel B20;

- No campus da Universidade Estadual de Santa Cruz, em llhéus (BA), foi criada uma planta piloto de produção de biodiesel de

2000 éster metílico, a partir de óleo de dendê e gorduras residuais. A planta tem capacidade de produção de 1400 litros por dia;

- O primeiro documento patentário sobre a produção de ésteres 


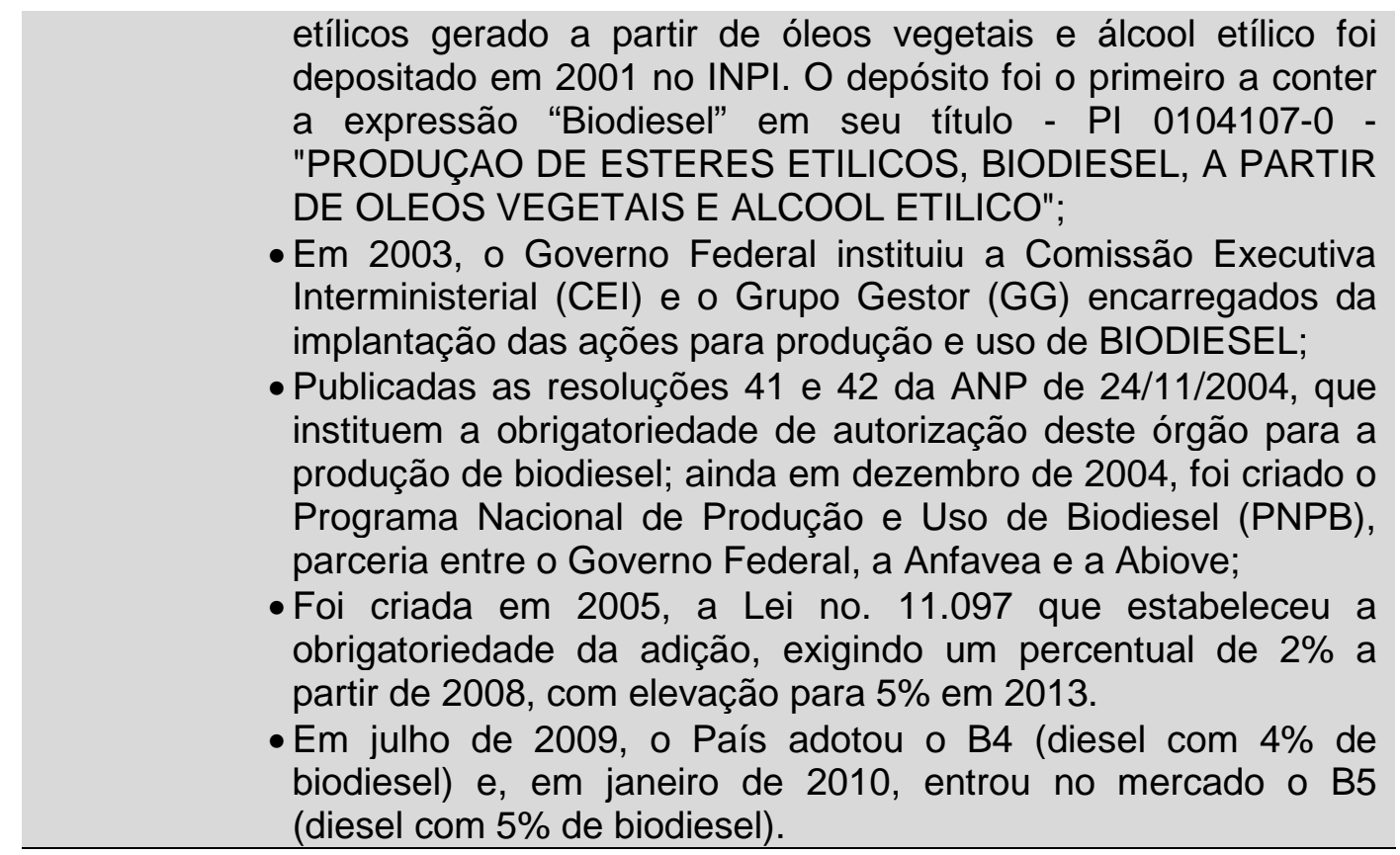

Fonte: Holanda (2004); Instituto Nacional de Propriedade Industrial (2008); Távora (2011).

No tocante à produção mundial de biodiesel, observa-se que houve forte crescimento nos últimos doze anos, correspondendo neste período com um aumento na produção de $2.812 \%$, uma média de $235 \%$ ao ano, totalizando em 2012 com 22,5 bilhões de litros/ano (REN, 2013).

Através da Lei 11.097, de janeiro de 2005 (BRASIL, 2005) o Brasil montou seu parque industrial e com a procura do B5, tornou-se um dos maiores produtores mundiais, conforme Gráfico 1 a seguir. Mantidas as condições atuais o Brasil, em tese, mantem-se sem existência de ameaça de desabastecimento no horizonte de curto prazo no país, isto mantidas as condições legais vigentes. 
Gráfico 1: Os 4 maiores produtores de Biodiesel no Mundo

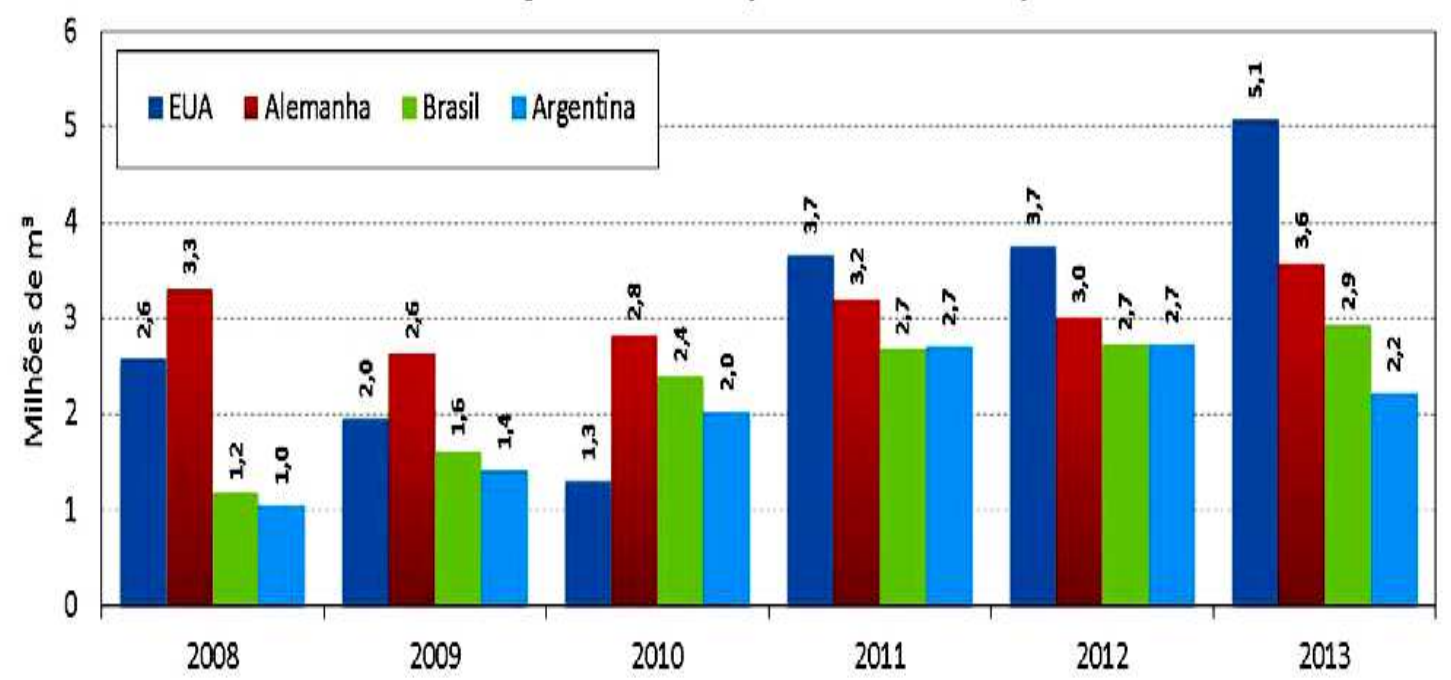

Fonte: Agência Nacional de Petróleo (2014); Brasil (2014)

De acordo com dados de fevereiro de 2014 (BRASIL, 2014), existem 57 usinas autorizadas para produzir e comercializar biodiesel e $90 \%$ das usinas estão localizadas nas regiões de CO, SE e S, conforme Figura 2 a seguir:

Figura 2 - Biodiesel: Localização das Unidades Produtoras

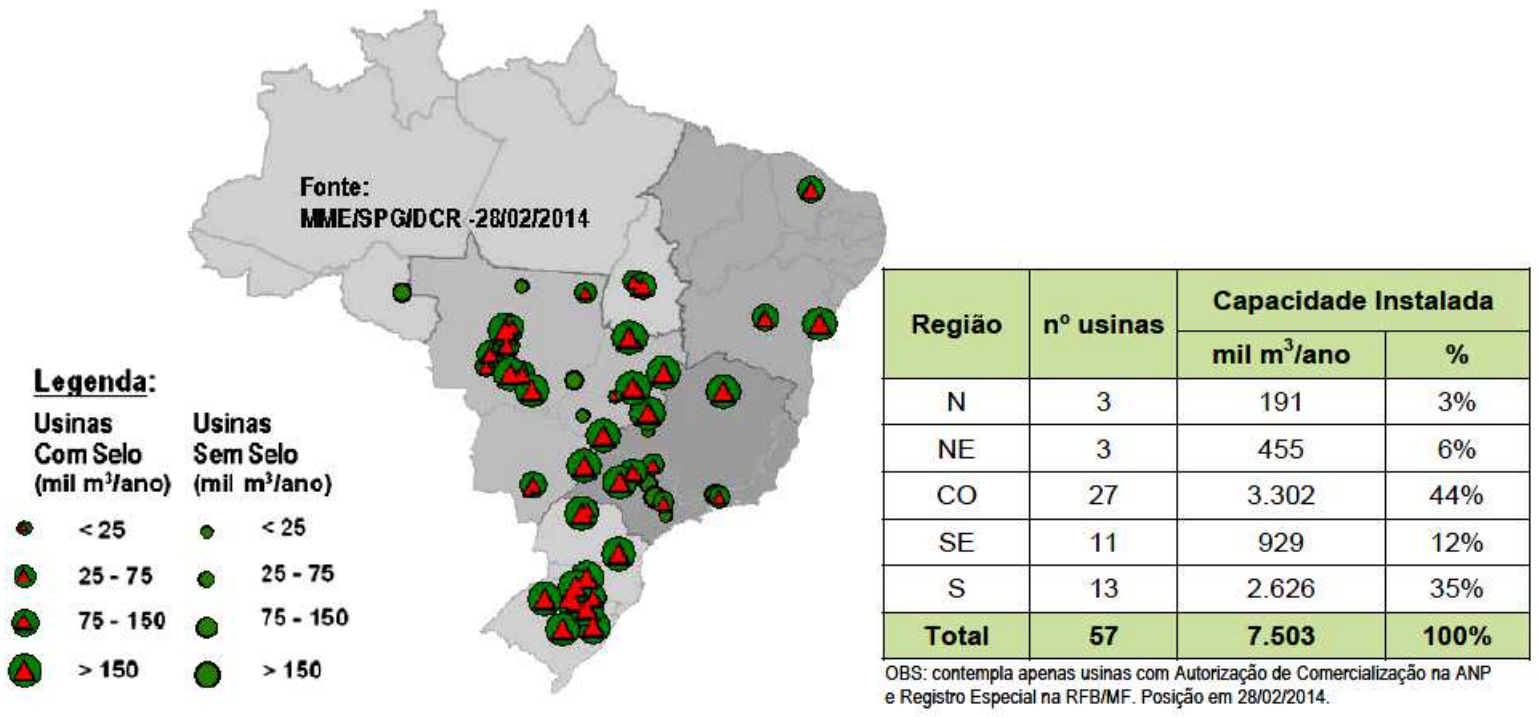

Fonte: Brasil (2014).

Observa-se que de 2005 a 2013 houve crescimento na capacidade instalada de biodiesel, em virtude da obrigatoriedade da regulamentação imposta no país obtendo atualmente uma capacidade instalada 7.553 bilhões de litros em fevereiro de 2014, conforme Gráfico 2 (AGÊNCIA NACIONAL DE PETRÓLEO, GÁS NATURAL E BIOCOMBUSTÍVEIS 2014; BRASIL, 2014). 
Gráfico 2 - Capacidade Instalada de Biodiesel no Brasil

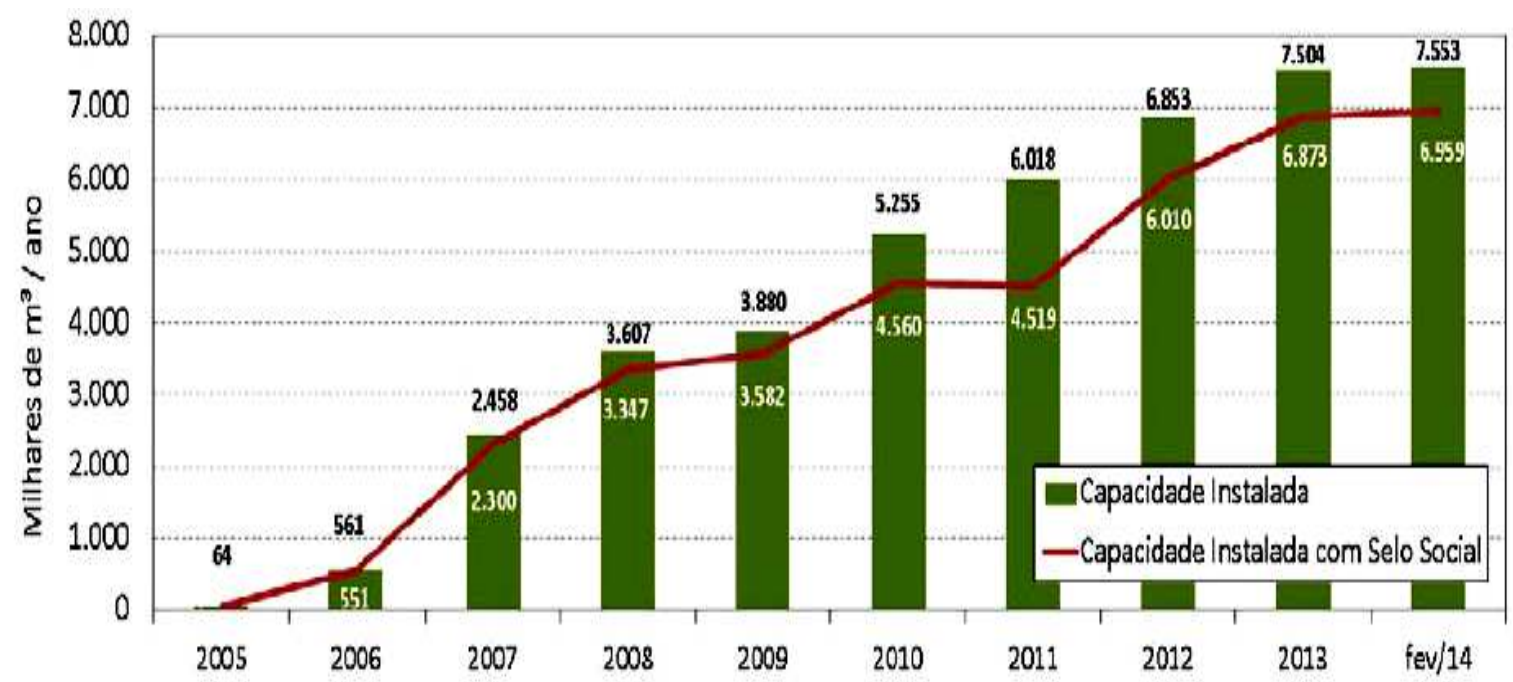

Fonte: Agência Nacional de Petróleo, Gás Natural e Biocombustíveis (2014) e Brasil (2014).

A produção nacional de biodiesel em 2013 foi de cerca de 2,91 bilhões de litros, com dados finais de 2013 e nos últimos 3 anos a média registrada foi de 2,7 bilhões de litros/ano, conforme Gráfico 3 (AGÊNCIA NACIONAL DE PETRÓLEO, GÁS NATURAL E BIOCOMBUSTÍVEIS , 2014; BRASIL, 2014). Com relação à capacidade instalada e a produção nos últimos anos, observa-se um alto índice de ociosidade, girando em média de 59,34\% nos períodos obrigatório da adição de biodiesel de 2008 a 2013.

\section{Gráfico 3 - Produção de Biodiesel no Brasil}

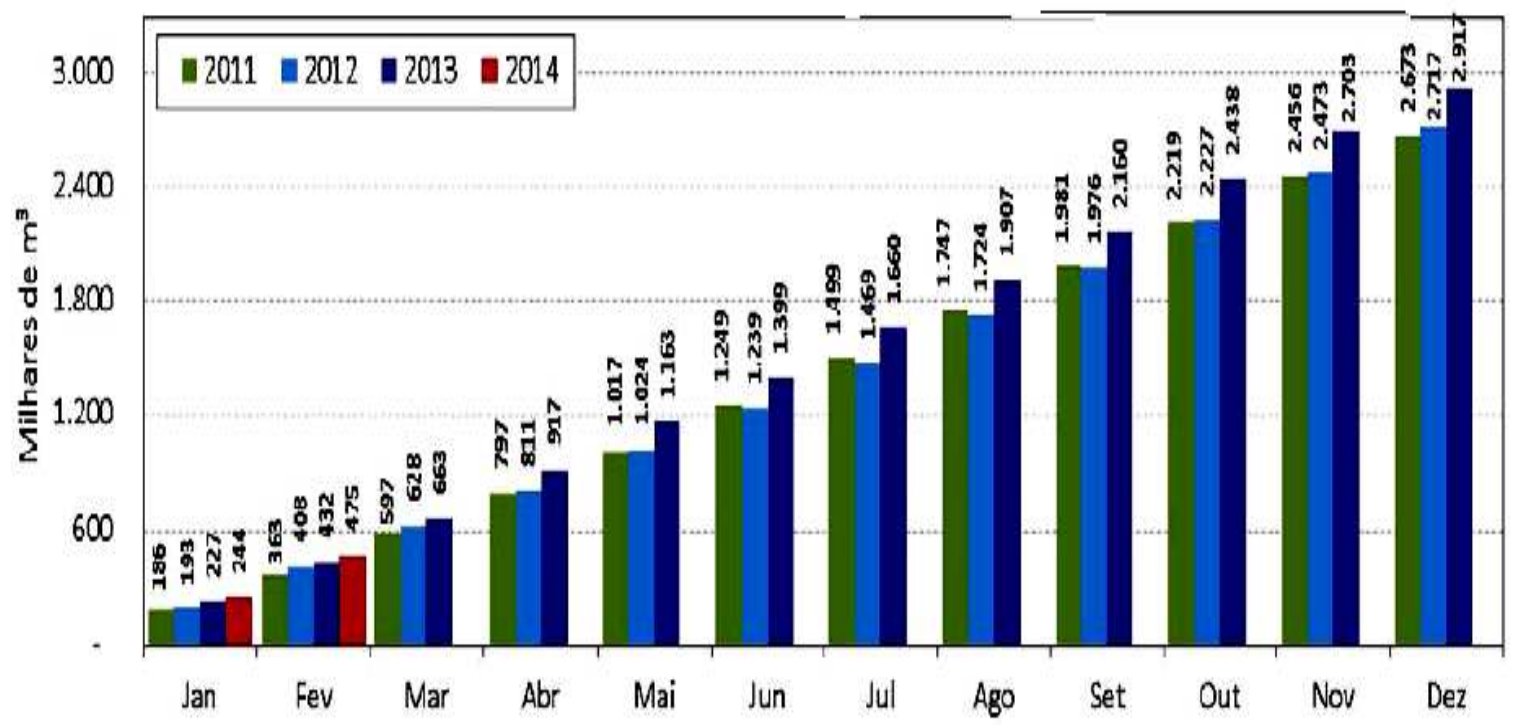

Fonte: Agência Nacional de Petróleo, Gás Natural e Biocombustíveis (2014) e Brasil (2014). 
Convém observar-se que o óleo de soja representou entre 2008 e 2013 a principal matéria-prima empregada na produção de biodiesel no Brasil, com uma média de $76 \%$ neste período, seguido de sebo bovino (16\%), óleo de algodão (4\%) e outras matérias-primas (4\%), conforme Tabela 1.

Tabela 1 - Matérias-primas utilizadas para produção de biodiesel no Brasil

\begin{tabular}{|l|l|l|l|l|l|l|}
\hline Matéria-prima & $\mathbf{2 0 0 8}$ & $\mathbf{2 0 0 9}$ & $\mathbf{2 0 1 0}$ & $\mathbf{2 0 1 1}$ & $\mathbf{2 0 1 2}$ & $\mathbf{2 0 1 3}$ \\
\hline Óleo de soja & $69 \%$ & $78 \%$ & $82 \%$ & $81 \%$ & $75 \%$ & $73 \%$ \\
\hline Sebo bovino & $18 \%$ & $16 \%$ & $14 \%$ & $13 \%$ & $17 \%$ & $20 \%$ \\
\hline Óleo de algodão & $2 \%$ & $4 \%$ & $2 \%$ & $3 \%$ & $5 \%$ & $2 \%$ \\
\hline Outras & $12 \%$ & $2 \%$ & $2 \%$ & $3 \%$ & $3 \%$ & $4 \%$ \\
\hline \\
$\begin{array}{l}\text { Fonte: Elaborado com dados da Agência Nacional de Petróleo, Gás Natural e } \\
\text { Biocombustíveis (2014) e Brasil (2014). }\end{array}$
\end{tabular}

Ao fim, ressalta-se o entendimento de que a temática do biodiesel seja extremamente relevante para o país, uma vez que esta modalidade de biocombustível além de poder se concretizar como um importante produto para exportação, pode ainda cumprir um papel importante no fortalecimento da base agroindustrial brasileira e no incremento da sustentabilidade da matriz energética nacional, além de se apresentar propícia à geração de novos empregos e renda no campo, e incorporar benefícios ambientais relevantes.

\section{OUTROS CONCEITOS RELEVANTES}

No âmbito geral do presente trabalho e em paralelo aos conceitos técnicos e mercadológicos envolvidos sobre o biodiesel, faz-se necessário abordar outros conteúdos tão relevantes quanto os tópicos já abordados, em vista à melhor compreensão acerca do cerne do presente estudo, bem como em fornecer um embasamento executivo para o artigo.

Assim, com o objetivo de lastrear a metodologia adotada, na sequencia, salienta-se um bojo de conceitos de relativa importância para a execução do trabalho, quais sejam: (i) conceitos de Pesquisa, Desenvolvimento e Inovação (PD\&I); (ii) conceitos de Indicadores científicos e Tecnológicos; e de (iii) Prospecção Tecnológica. Ressalta-se ainda, que autores da literatura já reconheceram o mérito de tais argumentos, destacando-os em seus trabalhos (CENTRO DE GESTÃO E 
ESTUDOS ESTRATÉGICOS, 2008; HAYASHI et al., 2006; LA VEGA, 2010; ; PERUCCHI; GARCIA, 2012;).

\section{Pesquisa, desenvolvimento \& inovação (PD\&l)}

As atividades de Pesquisa e Desenvolvimento são fundamentais na geração e disseminação de Tecnologia, norteando a produção de novos conhecimentos frequentemente pela experimentação (ORGANIZAÇÃO PARA COOPERAÇÃO E DESENVOLVIMENTO ECONÔMICO, 2010).

O emblemático conceito sobre desenvolvimento proferido pelo professor Adbus Salam, Prêmio Nobel de Física (1979), reflete bem a inmportância desse conceito no cenário científico, tecnológico e inovativo. Segundo ele

O desenvolvimento se define quase exclusivamente em termos de
capacidade de geração autônoma do conhecimento, da capacidade de
disseminá-lo e da capacidade de utilizá-lo. Esta é a verdadeira diferença
entre os países cujos cidadãos são capazes de realizar plenamente o seu
potencial como seres humanos e aqueles que não têm esta capacidade
(NUSSENZVEIG, 1994, p. 73 ).

Desta forma, entende-se que o desenvolvimento da ciência, tecnologia e inovação, bem como suas interconexões, são considerados determinantes tanto para garantir não apenas o crescimento econômico e o bem-estar social, como também, a criação de emprego e o aumento da competitividade no ambiente internacional. Contudo, esse mesmo desenvolvimento e a disseminação da ciência e da tecnologia se compõem em um processo intrincado, arrojado e matizado, justamente por causa da multiplicidade e intensidade de associações e afinidades entre todos os componentes dos Sistemas de Pesquisa, Desenvolvimento e Inovação.

Assim, em comum, os sistemas de Pesquisa e Desenvolvimento se apresentam de acordo com as seguintes modalidades: (i) Pesquisa Básica; (ii) Pesquisa Aplicada; (iii) Desenvolvimento Experimental. A Pesquisa Básica, Pura, ou Fundamental é a pesquisa feita com objetivo de aumentar conhecimentos científicos, sem direcionamento específico para a sua aplicação prática. Já a Pesquisa Aplicada se dedica à busca de novos conhecimentos voltados àsoluções sobre problemas previamente definidos, enquanto que ao Desenvolvimento Experimental, pode ser necessário alocar determinados fundos para a realização de trabalho adicional com foco experimental ou teórico, para melhor compreender os mecanismos que estão na base dos fenômenos estudados (TEIXEIRA, 2011). 
Infere-se daí que a importância da Pesquisa e Desenvolvimento na estrutura da inovação não possa ser negada. Onde quer que haja sinais de um esforço em P\&D, deduz-se que algum grau de inovação deva estar ocorrendo. Contudo, a recíproca nem sempre é verdadeira: nem todas as atividades inovadoras terão necessariamente atividades explícitas de P\&D - pelo menos em sentido definido para inovação pelos padrões atuais (MARTINS et al., 2013). Em suma, as atividades de P\&D podem ser entendidas como "marcadores genéticos” para a inovação.

Desta forma, para a análise ou avaliação da inovação em atividades científicas ou tecnológicas em um dado projeto, faz-se necessário compor um trabalho estatístico baseado em análises básicas e emprego de indicadores específicos para mensuração dos esforços e aspectos científicos e tecnológicos (LA VEGA, 2010; PERUCCHI; GARCIA, 2012).

\section{Indicadores científicos e tecnológicos}

Nos cenários científicos e tecnológicos, indicador é um substantivo concreto, mensurável, uma medida de síntese - de preferência estatística - com base na quantidade ou intensidade de um conjunto de parâmetros ou de atributos. Conforme Ferreira, Cassiolato e Gonzales (2009, p. 56):

O indicador é uma medida, de ordem quantitativa ou qualitativa, dotada de signifi cado particular e utilizada para organizar e captar as informações relevantes dos elementos que compõem o objeto da observação. É um recurso metodológico que informa empiricamente sobre a evolução do aspecto observado.

Em uma relevante publicação a cerca da mensuração dos sistemas de CT\&I nos estados brasileiro, Rocha e Ferreira (2004) publicaram que no âmbito da ciência, tecnologia e inovação, os indicadores são considerados como conjuntos específicos de parâmetros e atributos voltados à indicação da intensidade das atividades de pesquisa e desenvolvimento nos meios científicos e tecnológicos. Disso, fica depreendido que há um amplo espectro de indicadores, simples e complexos, que em comum, ambos necessitam de medidas de coleta acuradas e adequadas. Para isto, faz-se necessário se estabelecer uma estrutura conceitual complexa, com construções teóricas e equivalência empírica concreta (metodologias de coleta).

Com o atual aumento da relevância do papel da Ciência, Tecnologia e sobretudo da Inovação, como determinantes do desenvolvimento econômico e social, os centros de pesquisas estão praticamente sendo forçados a medir a sua 
produtividade das pesqquisas através de indicadores indviduais e grupais, cujo foco será exclusivamente a identificação daquelas instituições e áreas com maiores potencialidades e para o estabelecimento das preferencias no momento de adequações dos recursos públicos (MEULEMAN; MAESENEIRE, 2012).

Há basicamente duas famílias fundamentais de indicadores de Ciência e Tecnologia (C\&T) que são geralmente usados para mensurar a questão da inovação: (i) recursos direcionados à P\&D; e (ii) estatísticas de depósitos de patentes. Têm-se tambem, indicadores bibliométricos e vários outros tipos de indicadores que oferecem informações suplementares (ORGANIZAÇÃO PARA COOPERAÇÃO E DESENVOLVIMENTO ECONÔMICO, 2005; 2010; WINTER, 2013). Valendo ressaltar que as patentes podem ser consideradas como indicadores de esforço inovativo (GARCIA, 2004).

Para Silva, Medeiros Filho e Pires (2013), a análise dos esforços para a construção de indicadores de ciência e tecnologia (C\&T) no Brasil remontam à decadade 1970 quando houve uma mobilização entre a UNESCO e o CNPq para a construção de um sistema estatístico para C\&T que funcionaria como ferramenta de suprimento à comparabilidade internacional, através da definição de indicadores e um plano para coleta de dados. Nos dias atuais, o Diretório dos Grupos de Pesquisa do CNPq é composto por pesquisas coletivas e integradas por grupos de pesquisas, em diversas linhas de abordagem tecnológica, que vem crescendo no espaço nacional dentro das instituições de ensino. O CNPq disponibiliza tais informações, sobre cada grupo e linha de pesquisa em atividade no Brasil, de modo que possam ser utilizadas pela comunidade científica e/ou pelas agências de fomento brasileiras (PERUCCHI; GARCIA, 2012).

\section{Prospecção tecnológica}

Atualmente as ferramentas de prospecções tecnológicas têm sido decisivas na operacionalização da Ciência e Tecnologia, bem como na fundamentação nos processos de tomada de decisão referentes à pesquisa, ao desenvolvimento e à inovação (QUINTELLA et al., 2009). É crucial na identificação de oportunidades e necessidades relevantes, entendendo que os desenvolvimentos científicos e tecnológicos resultam de complexa interação entre os atores diversos, das necessidades sociais, oportunidades e restrições econômicas e da consciência ambiental entre outros (COELHO et al., 2010). 
A utilização de métodos potenciais e técnicas de apoio, para a tomada de decisões no estabelecimento de Políticas de Ciência, Tecnologia e Inovação, têm aumentado no Brasil, resultado de profundas mudanças no país nos aspectos relacionados à globalização da economia e à aceleração das mudanças tecnológicas. Prever o futuro tornou-se um elemento de extrema importância, a fim de aumentar a competitividade das empresas brasileiras e do próprio país, pois permite vislumbrar avanços, saltos tecnológicos, tendências e descontinuidades, novas perspectivas e mapas de oportunidades (COELHO et al., 2010).

Muitos novos métodos, técnicas e ferramentas atualmente usadas em estudos prospectivos resultaram de avanços na tecnologia e ciência da informação. Entre eles, destacam-se a cientometria e bibliometria, tradicionalmente utilizado pela ciência da informação para medir a produtividade científica e identificar redes de cooperação em C\&T. O advento de recursos de informação em formato eletrônico, acessíveis ao grande público, tornou menores os esforços de coleta e análise da informação (COELHO; SILVA, 2003).

\section{METODOLOGIA}

Para a realização deste trabalho adotam-se procedimentos descritivos, qualitativos e exploratórios, incluindo investigação bibliográfica e uma prospecção dos indicadores científicos e tecnológicos extraídos do Diretório dos Grupos de Pesquisa (DGP/CNPq) em junho de 2013.

Desenvolvido pelo CNPq desde 1992, DGP/CNPq constitui-se de bases de dados que contêm informações sobre os grupos de pesquisa em atividade no Brasil e que estão localizados em universidades, instituições isoladas de ensino superior, institutos de pesquisa científica, institutos tecnológicos e laboratórios de pesquisa e desenvolvimento de empresas estatais ou ex-estatais, sendo excluídos os grupos localizados nas empresas do setor produtivo (CONSELHO NACIONAL DE DESENVOLVIMENTO CIENTíFICO E TECNOLÓGICO, 2013a).

Cada grupo é situado no espaço (Divisão Regional, Unidade Federativa e Instituição) e no tempo. As informações do DGP/CNPq são alimentadas e atualizadas pelos líderes de cada grupo e a cada dois anos um censo é realizado pelo CNPq (CONSELHO NACIONAL DE DESENVOLVIMENTO CIENTÍFICO E TECNOLÓGICO, 2013a). Para este trabalho, foi utilizada a base censitária de 2011 
e as atualizações dos dados de junho de 2013. Cabe ressaltar que os dados finais consolidados do censo 2013 ainda não foram divulgados.

Os dados foram coletados na base textual do DGP/CNPq em junho de 2013 com a utilização da palavra-chave "biodiesel". Em seguida, foram selecionados apenas os grupos considerados válidos, ou seja, que foram certificados pelos dirigentes de pesquisa das instituições aos quais pertencem. Foram identificados 372 grupos, mas dois grupos (Grupo de Pesquisa em Processos Químicos e Tecnológicos e Grupo de Pesquisas em Química), ambos da Universidade Federal de Alagoas (UFAL) e localizados na região Nordeste foram excluídos da amostra por não estarem certificados.

Os dados obtidos permitiram analisar: (i) o número de grupos de pesquisas atualmente cadastrados e sua distribuição nas cinco regiões do Brasil; (ii) a interação dos grupos com o setor produtivo; (iii) o número de linhas de pesquisa exploradas pelos grupos; (iv) as áreas do conhecimento e; (v) o quantitativo de pessoas alocadas em cada grupo.

\section{RESULTADOS E DISCUSSÃO}

A década de 1970 foi marcada pelo surgimento do primeiro grupo de pesquisa relacionado ao biodiesel ${ }^{27}$, comandado pela pesquisadora Francisca Pessôa de França e ligado às áreas de engenharias; engenharia química da Universidade Federal do Rio de Janeiro (UFRJ), na região sudeste do Brasil. O mais recente é o APLICABIO de 2013, ligado às áreas das ciências biológicas; microbiologia do Instituto Federal da Bahia (IFBA), no Nordeste brasileiro.

De 1975 até junho de 2013 o número de grupos de pesquisa certificados saltou para 370, sendo que 132 grupos estavam localizados na região Sudeste, seguido do Nordeste com 109 grupos, o Sul com 72, o Centro-Oeste com 37 e o Norte com 20 grupos como mostra a Tabela 2.

Com relação à Tabela 2, algumas ponderações são necessárias para uma melhor compreensão. Na década 1980, o governo brasileiro descontinuou o Programa Nacional de Óleos Vegetais para Produção de Energia (Pro-Óleo),

27 De 1964 a 1985, o Brasil vivia sob o domínio de uma ditadura militar. Neste período, foram estimulados vários programas para a produção de combustíveis com base em produtos agrícolas com o objetivo de reduzir a dependência brasileira do petróleo importado do Oriente Médio. Entre os programas destacam-se Programa Nacional de Óleos Vegetais para Produção de Energia (Pro-Óleo) e o Programa Nacional do Álcool (Proálcool). 
paralisando todos os seus subprogramas. Somente na segunda metade da década de 1990, o interesse em biocombustíveis foi retomado e junto com ele, crescimento no número de grupos de pesquisa.

Tabela 2 - Grupos de pesquisa em Biodiesel de 1975 a junho de 2013

\begin{tabular}{l|c|c|c}
\hline Ano de formação & $\begin{array}{c}\text { Número de } \\
\text { grupos de } \\
\text { pesquisa }\end{array}$ & Frequência relativa & $\begin{array}{c}\text { Frequência } \\
\text { acumulada }\end{array}$ \\
\hline De 1975 a 1980 & 5 & $1,35 \%$ & $1,35 \%$ \\
De 1981 a 1885 & 5 & $1,35 \%$ & $2,70 \%$ \\
De 1986 a 1990 & 13 & $3,51 \%$ & $6,22 \%$ \\
De 1991 a 1995 & 27 & $7,30 \%$ & $13,51 \%$ \\
De 1996 a 2000 & 48 & $12,97 \%$ & $26,49 \%$ \\
De 2001 a 2005 & 61 & $16,49 \%$ & $42,97 \%$ \\
De 2006 a 2010 & 163 & $44,05 \%$ & $87,03 \%$ \\
De 2011 a 2013 & 48 & $12,97 \%$ & $100 \%$ \\
\hline \multicolumn{4}{l}{ Fonte: Conselho Nacional de Desenvolvimento Científico e Tecnológico (2013). }
\end{tabular}

Os estudos para a reestruturação da matriz energética brasileira apontaram a necessidade de criação de uma política nacional para a substituição paulatina do óleo diesel pelo biodiesel de produtos vegetais e da biomassa (MATTEI, 2007). Em 1998, a ANP autorizou a realização de testes e comercialização de combustíveis não especificados, entre eles o biodiesel. Com isso, observa-se na Tabela 3 o aumento no número de grupos de pesquisas credenciados no DGP/CNPq. Dos 48 grupos cadastrados no período de 1996 a 2000, 64,58\% foram criados a partir de 2008.

O número de grupos continuou a crescer na década de 2000 em dois momentos distintos. O primeiro de 2001 a 2005 com a criação de 61 grupos pode ter ocorrido em virtude da instituição do Probiodiesel, pela Secretaria de Política Tecnológica do Ministério da Ciência e Tecnologia. Junto com o Probiodiesel, uma rede de pesquisa foi organizada com o intuito de promover a competitividade técnica, econômica e ambiental do biodiesel em relação ao diesel disponível comercialmente (RAMOS; WILHELM, 2005).

O segundo momento coincide com o primeiro mandato do presidente Luis Inácio Lula da Silva (2003-2006), quando o Probiodiesel foi descontinuado por não contemplar aspectos sociais e em seu lugar foi instituído o Programa Nacional de Produção e Uso de Biodiesel (PNPB). Assim, de 2006 a 2010, foram credenciados 163 grupos junto ao DGP/CNPq, englobando diferentes áreas do conhecimento que não faziam parte do escopo original (dominado pelas engenharias), o que mostra a boa receptividade e o aumento da importância da temática biodiesel no cenário científico brasileiro. 
Entre as novas áreas estão grupos relacionados com economia, administração e direito, das ciências sociais aplicadas; tecnologia de alimentos e recursos pesqueiros, das ciências agrárias e; bioquímica e botânica, das ciências biológicas.

Com relação à distribuição média de grupos por Estados de cada região, a região Sudeste lidera com 33 grupos, seguida do Sul com 24 grupos, do Nordeste com 12, Centro-Oeste com $9,25^{28}$ e o Norte com 2,86. A Tabela 3 apresenta uma distribuição dos grupos de pesquisas pelas cinco regiões do Brasil e seus respectivos Estados.

\begin{tabular}{|c|c|c|c|c|c|}
\hline \multirow[t]{2}{*}{ Região } & \multicolumn{2}{|c|}{$\begin{array}{l}\text { Distribuição } \\
\text { dos Grupos }\end{array}$} & \multicolumn{3}{|c|}{ Representatividade por Estado } \\
\hline & $\begin{array}{c}\text { № } \\
\text { Grupos }\end{array}$ & $\begin{array}{c}\% \\
\text { Nacional }\end{array}$ & Estado & $\begin{array}{l}\text { Número de } \\
\text { grupos }\end{array}$ & $\begin{array}{c}\% \\
\text { Regional }\end{array}$ \\
\hline \multirow{4}{*}{ Sudeste } & \multirow{4}{*}{132} & \multirow{4}{*}{$35,68 \%$} & São Paulo & 49 & $37,12 \%$ \\
\hline & & & Rio de Janeiro & 42 & $31,82 \%$ \\
\hline & & & Espírito Santos & 7 & 5,30 \\
\hline & & & Minas Gerais & 34 & $25,76 \%$ \\
\hline \multirow{3}{*}{ Sul } & \multirow{3}{*}{72} & \multirow{3}{*}{$19,46 \%$} & Paraná & 42 & $58,33 \%$ \\
\hline & & & Santa Catarina & 22 & $30,56 \%$ \\
\hline & & & Rio Grande do Sul & 8 & $11,11 \%$ \\
\hline \multirow{4}{*}{ Centro-Oeste } & \multirow{4}{*}{37} & \multirow{4}{*}{$10,00 \%$} & Mato Grosso & 10 & $27,03 \%$ \\
\hline & & & Mato Grosso do Sul & 15 & $40,54 \%$ \\
\hline & & & Goiás & 6 & $16,22 \%$ \\
\hline & & & Distrito Federal & 6 & $16,22 \%$ \\
\hline \multirow{9}{*}{ Nordeste } & \multirow{9}{*}{109} & \multirow{9}{*}{$29,46 \%$} & Bahia & 31 & $28,44 \%$ \\
\hline & & & Sergipe & 9 & $8,26 \%$ \\
\hline & & & Alagoas & 4 & $3,67 \%$ \\
\hline & & & Pernambuco & 13 & $11,93 \%$ \\
\hline & & & Paraíba & 16 & $14,68 \%$ \\
\hline & & & Rio Grande do Norte & 10 & $9,17 \%$ \\
\hline & & & Ceará & 12 & $11,01 \%$ \\
\hline & & & Piauí & 7 & $6,42 \%$ \\
\hline & & & Maranhão & 7 & $6,42 \%$ \\
\hline \multirow{7}{*}{ Norte } & \multirow{7}{*}{20} & \multirow{7}{*}{$5,41 \%$} & Tocantins & 6 & $30,00 \%$ \\
\hline & & & Pará & 4 & $20,00 \%$ \\
\hline & & & Amapá & - & - \\
\hline & & & Amazonas & 8 & $40,00 \%$ \\
\hline & & & Roraima & 1 & $5,00 \%$ \\
\hline & & & Acre & - & - \\
\hline & & & Rondônia & 1 & $5,00 \%$ \\
\hline
\end{tabular}

Fonte: Conselho Nacional de Desenvolvimento Científico e Tecnológico (2013)

Pondera-se que as tecnologias em biodiesel atinjam uma maturidade que acarretará em uma diminuição de criação de novos grupos, conforme estimado por extrapolação tendo como base o ano de 2013.

Já a análise do indicador interação dos grupos de pesquisa com o setor produtivo mostrou que a região Sudeste, a mais industrializada do Brasil, foi a que

${ }^{28} \mathrm{O}$ cálculo levou em consideração os três Estados que compõem a região Centro-Oeste mais o Distrito Federal. 
mais estabeleceu parcerias com o setor produtivo 116, seguida pelo Nordeste com 61, Sul com 45, Centro-Oeste com 13 e Norte com 6, como mostra o Gráfico 4.

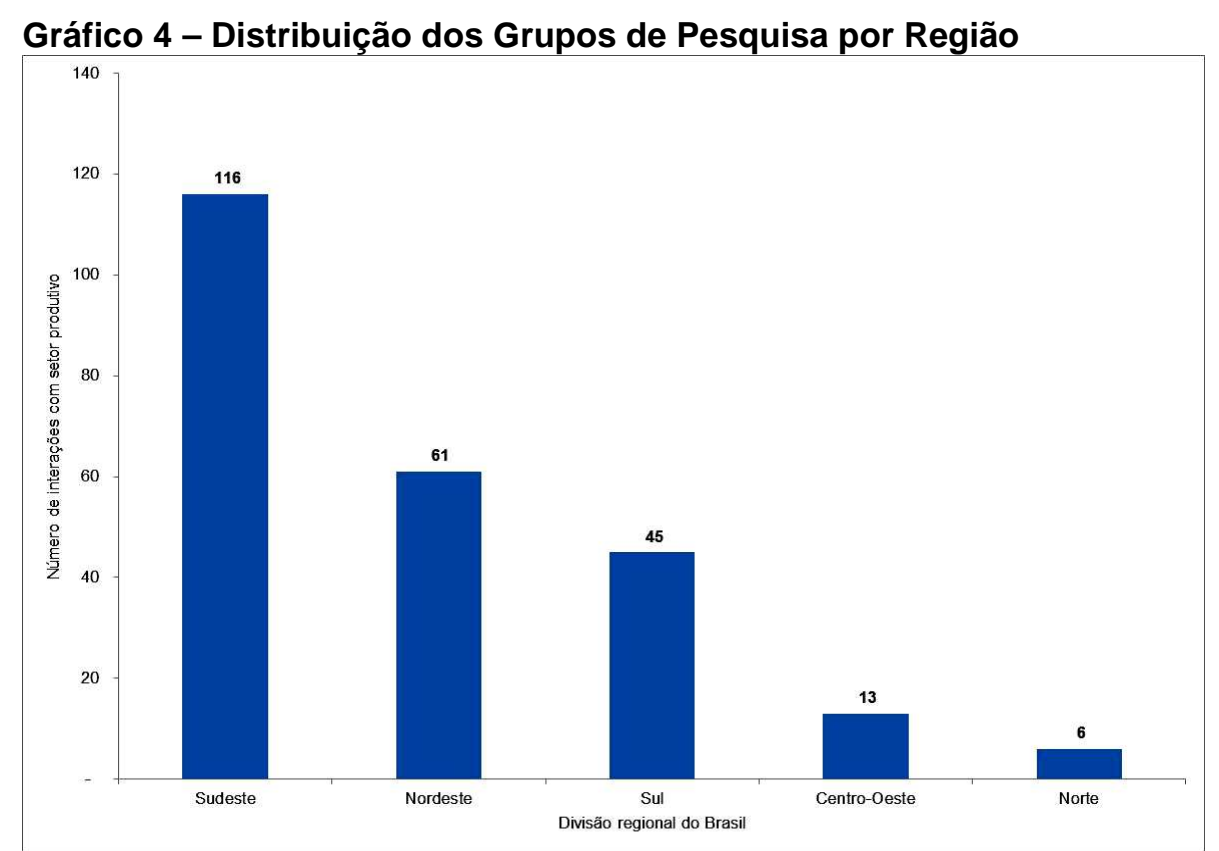

Fonte: Conselho Nacional de Desenvolvimento Científico e Tecnológico (2013)

Mais uma vez, se levar em conta o número de Estados que compõe cada região, os valores do Sul superam em quase $50 \%$ os do Nordeste. O Sudeste se mantém na liderança com uma média de quase 30 interações por estado, coerente com o alto grau de industrialização da região.

Já a região Centro-Oeste demonstrou pouca interação com o setor produtivo apesar de responder por quase $50 \%$ da produção de biodiesel no país. Este indicador reforça a ideia de que existe ainda um distanciamento da Academia com o setor empresarial.

Quanto aos indicadores números de linhas de pesquisa e contingente de recursos humanos organizados em função dessas, constatou-se que 47,30\% dos grupos exploram entre uma e cinco linhas, como mostra a Tabela 4. Vale salientar, que a região Sudeste é a que possui uma maior diversidade de linhas de pesquisa, seguida do Nordeste, Sul, Centro-Oeste e Norte.

Tabela 4 - Número de Linhas e Grupos de Pesquisa de 1975 a 2013

\begin{tabular}{l|c|c|c}
\hline Número de linhas & $\begin{array}{c}\text { Número de grupos de } \\
\text { pesquisa }\end{array}$ & Frequência relativa & $\begin{array}{c}\text { Frequência } \\
\text { acumulada }\end{array}$ \\
\hline De 1 a 5 & 175 & $40,30 \%$ & $40,30 \%$ \\
De 6 a 10 & 140 & $37,84 \%$ & $85,14 \%$ \\
De 11 a 15 & 40 & $10,81 \%$ & $95,95 \%$ \\
De 16 a 20 & 10 & $2,70 \%$ & $98,65 \%$ \\
Mais de 20 & 5 & $1,35 \%$ & $100,00 \%$ \\
\hline
\end{tabular}

Fonte: Conselho Nacional de Desenvolvimento Científico e Tecnológico (2013). 
Quanto ao contingente de recursos humanos, estes são classificados pelo CNPq como: pesquisadores, estudantes e técnicos. Nesta análise, somente o quantitativo de pesquisadores e técnicos foi levado em consideração. Assim, observou-se que o Grupo de Nanotecnologia Aplicada ao Agronegócio tinha o maior número de pesquisadores cadastrados: 188; o Grupo Agroenergia - Oleaginosas Alternativas Potenciais possuía o maior número de técnicos cadastrados: 34. Ambos os grupos são da Empresa Brasileira de Pesquisa Agropecuária (Embrapa). Contudo, $68,11 \%$ dos grupos possuem de 1 a 10 pesquisadores.

Já com relação ao número de técnicos, $48,92 \%$ possuem de 1 a 5 técnicos como cadastrados como membros do grupo. Entretanto, um dado chamou atenção: $47,30 \%$ dos grupos não possuem técnicos em sua equipe. A Tabela 5 apresenta uma distribuição do número de pesquisadores e técnicos pelos grupos de pesquisa.

Tabela 5 - Número de Pessoas nos Grupos de Pesquisas de 1975 a 2013

\begin{tabular}{l|c|c|c|c}
\hline \multicolumn{3}{|c|}{ Pesquisadores } & \multicolumn{2}{c}{ Técnicos } \\
\hline \multicolumn{1}{c|}{ pessoal } & $\begin{array}{c}\text { № de grupos de } \\
\text { pesquisa }\end{array}$ & Frequência relativa & $\begin{array}{c}\text { № de grupos de } \\
\text { pesquisa }\end{array}$ & $\begin{array}{c}\text { № de grupos de } \\
\text { pesquisa }\end{array}$ \\
\hline De 1 a 5 & 115 & $31,08 \%$ & 181 & $48,92 \%$ \\
De 6 a 10 & 137 & $37,03 \%$ & 9 & $2,43 \%$ \\
De 11 a 15 & 71 & $19,19 \%$ & 1 & $0,27 \%$ \\
De 16 a 20 & 19 & $5,14 \%$ & 3 & $0,81 \%$ \\
Mais de 20 & 28 & $7,57 \%$ & 1 & $0,27 \%$ \\
\hline
\end{tabular}

Fonte: Conselho Nacional de Desenvolvimento Científico e Tecnológico (2013).

Em termos absolutos, foram identificadas 4.303 pessoas envolvidas com os grupos de pesquisa relacionados ao biodiesel, sendo 3.791 pesquisadores e 512 técnicos. Quanto à distribuição desse contingente por região, observou-se que a região Sudeste é que concentra maior número de pesquisadores e técnicos, seguida pelo Nordeste, Sul, Nordeste, Centro Oeste e Sul, como mostra o Gráfico 5 


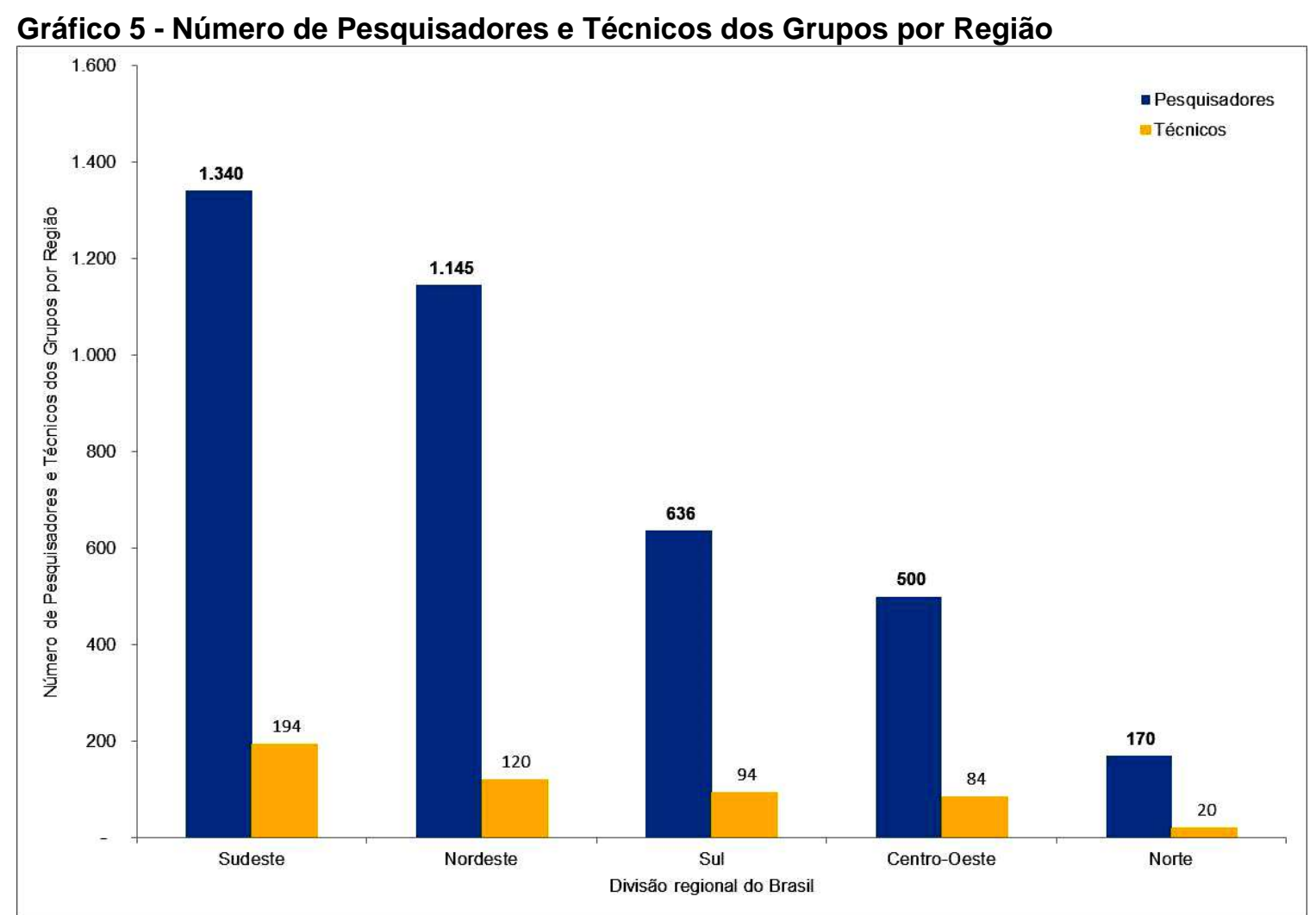

Fonte: Conselho Nacional de Desenvolvimento Científico e Tecnológico (2013).

Com relação aos números apresentados no gráfico acima, cabe ressaltar que os pesquisadores podem pertencer a vários grupos de pesquisa, inclusive a outras instituições e outros estados. Logo, esses números não indicam que a totalidade do contingente de pesquisadores esteja localizada nessas regiões, embora seja raro o pertencimento de um pesquisador a uma instituição de outro estado, de outra região.

Antes de abordar o indicador denominado grupos por área de áreas do conhecimento, algumas explicações são necessárias. As Áreas do Conhecimento representam um conjunto de conhecimentos que se inter-relacionam e que foram reunidos segundo a natureza do objeto de investigação com finalidades de ensino, pesquisa e aplicações práticas, proporcionando assim às instituições que atuam em ciência e tecnologia uma forma prática de sistematizar e divulgar informações sobre - desenvolvimento científico e tecnológico (COORDENAÇÃO DE APERFEIÇOAMENTO DE PESSOAL DE NÍVEL SUPERIOR, 2013). 
Esta hierarquização esta estruturada em quatro níveis, que vão do mais geral aos mais específicos, abrangendo 08 grandes áreas, a saber: 1. Ciências Exatas e da Terra; 2. Ciências Biológicas; 3. Engenharias; 4. Ciências da Saúde; 5. Ciências Agrárias; 6. Ciências Sociais Aplicadas; 7. Ciências Humanas; 8. Linguística, Letras e Artes; 9. Outros ${ }^{29}$ (CONSELHO NACIONAL DE DESENVOLVIMENTO CIENTíFICO E TECNOLÓGICO, 2013b).

$\mathrm{Na}$ análise geral do Brasil, a área que apresentou a maior concentração de grupos de pesquisa no Brasil foi Ciências Exatas e da Terra com 40\%, seguida das áreas de engenharias, Ciências Agrárias e Ciências Biológicas com 28,38, 17,30\% e $10,00 \%$ respectivamente.

Também foram identificados grupos nas áreas das Ciências Sociais Aplicadas (2,70\%), Ciências Humanas (0,81\%), Ciências da Saúde (0,54\%) e Linguística $(0,27 \%)$. Pode-se atribuir o surgimento desses grupos com o lançamento do PNPB em 2005 que tem como um dos pilares a inclusão social com a inserção da agricultura familiar na cadeia produtiva do biodiesel.

A região Sudeste apresenta um maior número de grupos de pesquisas e a área que de engenharias lidera com $34,09 \%$, seguida da área de ciências exatas e da terra com $31,06 \%$. Por outro lado, as regiões Centro-Oeste e Norte apresentam baixos números de grupos de pesquisa e a área de engenharias não apresenta nenhum índice de grupos de pesquisas relacionados ao biodiesel, como mostra o gráfico 6.

${ }^{29}$ Envolve: Bioética Ciências, Ambientais, Defesa e Divulgação Científica [8]. 
Gráfico 6 - Distribuição das Áreas de Conhecimento dos Grupos de Biodiesel no Brasil

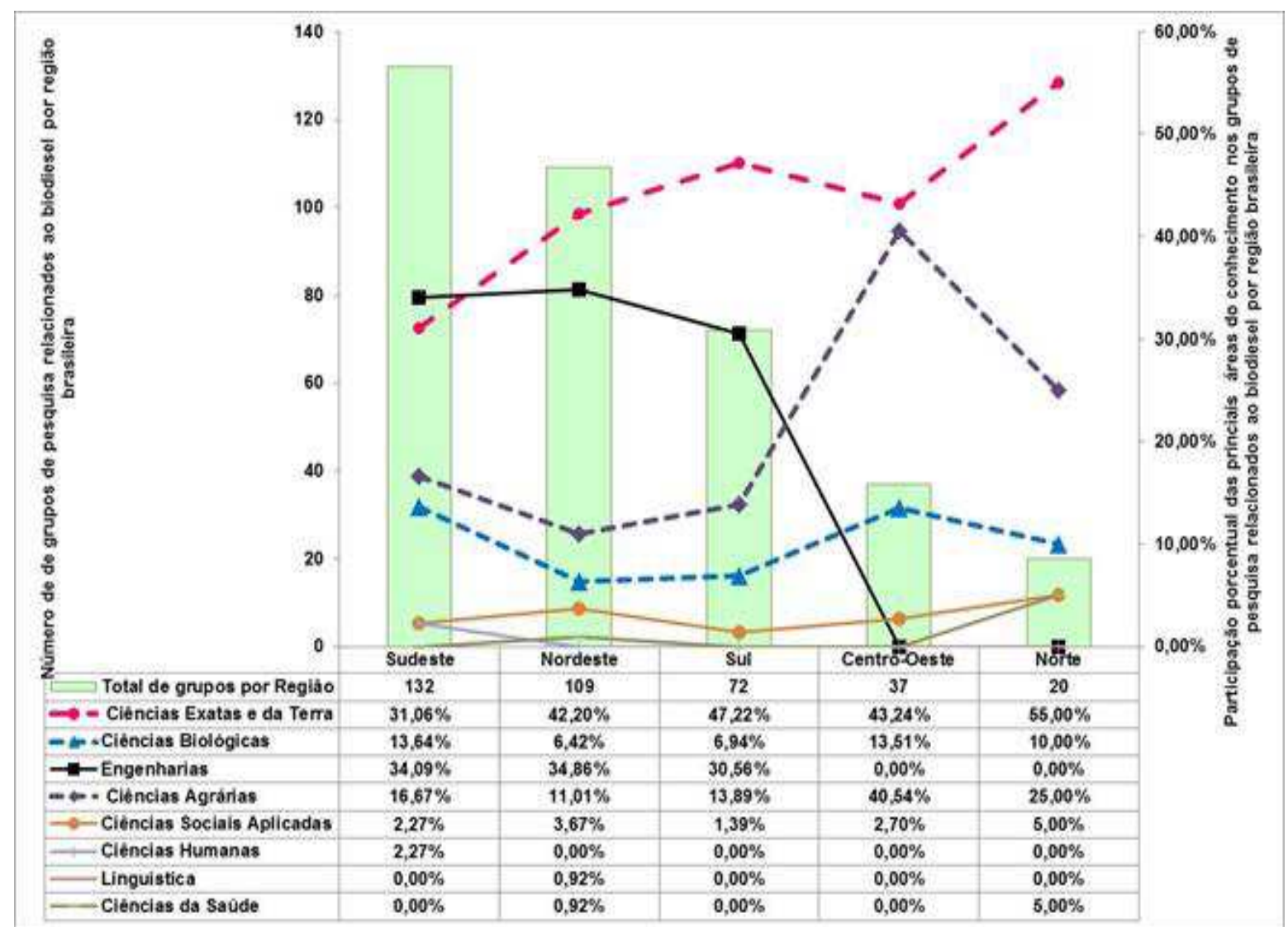

Fonte: Conselho Nacional de Desenvolvimento Científico e Tecnológico (2013).

\section{CONSIDERAÇÕES FINAIS}

Em termos de produção do biodiesel, o PNPB superou as expectativas de sua real capacidade de abastecimento, o que possibilitou o adiantamento dos prazos de implementação dos percentuais mínimos de sua mistura ao diesel, posicionando o país como um dos maiores produtores de biodiesel em nível mundial.

Com a crescente substituição paulatina do óleo diesel pelo biodiesel de produtos vegetais e da biomassa, observa-se um crescente números de pesquisas relevantes com a temática e consequentemente, o número de grupos de pesquisa aumentaram significativamente a partir da década de 2000. 
A pesquisa apontou que as regiões Sudeste, Sul e Centro-oeste lideram em todos os requisitos pesquisados e as regiões Nordeste e Norte apresentam grandes fragilidades em quase todos os requisitos.

A região Sudeste lidera o número de pesquisadores e técnicos, a distribuição média de grupos por Estados, a interação dos grupos de pesquisa com o setor produtivo e é também a que possui maior diversidade de linhas de pesquisa. $A$ grande novidade é a região Nordeste aparecendo na $2^{\underline{a}}$ posição da interação dos grupos de pesquisa com o setor produtivo e com relação ao número de pesquisadores e técnicos envolvidos na área em análise.

Ao se analisar a produção científica e tecnológica brasileira em biodiesel, o estudo aqui exposto, utilizando ferramentas de prospecção, aponta evidências de que as novas constituições de grupos de pesquisas espalhados no Brasil, tendo no seu escopo uma base técnico-científica que visa orientar as diversas áreas correlatas ao PNPB, foram decisivas para estimular o fomento à P\&D na cadeia produtiva do biodiesel.

Esse conjunto de condições consagrou o Brasil como um dos líderes em desenvolvimento tecnológico e o país hoje é um dos maiores contribuidores de artigos indexados, além de ser também um dos maiores depositantes de patentes no que se refere ao biodiesel. Por outro lado, observou-se que é ainda é incipiente a interação das pesquisas acadêmicas com o setor produtivo.

\section{REFERÊNCIAS}

ABRAMOVAY, R.; MAGALHÃES, R.O. Acesso dos agricultores familiares aos mercados de biodiesel: parcerias entre grandes empresas e movimentos sociais. In: CONFERÊNCIA DA ASSOCIAÇÃO INTERNACIONAL DE ECONOMIA ALIMENTAR E AGROINDUSTRIAL 2007, Londrina, Anais... Londrina: AIEA2.

AGÊNCIA NACIONAL DE PETRÓLEO, GÁS NATURAL E BIOCOMBUSTÍVEIS. Dados Estatísticos Mensais. Disponível em: <http://www.anp.gov.br>. Acesso em: 10 abr. 2014.

ARANSIOLA, E.F. et al. A review of current technology for biodiesel production: State of the art, Biomass and Bioenergy, v. 61, p. 276-297, 2014.

BRASIL. Ministério de Minas e Energia. Boletim mensal dos combustíveis Renováveis, Brasília, SPG, março, 2014. Disponível em: <http://www.mme.gov.br/spg/menu/publicacoes.html>. Acesso em: 15 nov. 2013. 
CENTRO DE GESTÃO E ESTUDOS ESTRATÉGICOS. Avaliação de políticas de ciência, tecnologia e inovação: diálogo entre experiências internacionais e brasileiras. Brasília: Centro de Gestão e Estudos Estratégicos, 249 p.; Il.; 2008.

CHAVANNE, G. Patente Belga BE 422,877, 1937.

COELHO, G.M. et al. Foresight estratégico: uso da abordagem metodológica no plano de gestão de uma agência de fomento a ciência, tecnologia e inovação.

Parcerias Estratégicas-CGEE, Brasília-DF, v. 30, p. 129-159, 2010.

CONSELHO NACIONAL DE DESENVOLVIMENTO CIENTÍFICO E TECNOLÓGICO. Grupos de pesquisa. Disponível em:

<http://memoria.cnpq.br/gpesq/apresentacao.htm>. Acesso em: Out. 2013a.

CONSELHO NACIONAL DE DESENVOLVIMENTO CIENTÍFICO E TECNOLÓGICO . Áreas do Conhecimento. Disponível em:

<http://memoria.cnpq.br/areasconhecimento/index.htm>. Acesso em: Out. 2013b.

COORDENAÇÃO DE APERFEIÇOAMENTO DE PESSOAL DE ENSINO

SUPERIOR. Tabela de Áreas de Conhecimento. <http://www.capes.gov.br/ avaliacao/tabela-de-areas-de-conhecimento>. Acesso em: Out. 2013.

FERNANDES, A. C. et al. Academy-industry links in Brazil: evidence about channels and benefits for firms and researchers. Science and Public Policy, v. 37, n. 7, p. 485-498, 2010.

FERREIRA, H.; CASSIOLATO, M.; GONZALEZ, R. Uma experiência de desenvolvimento metodológico para avaliação de programas: o modelo lógico do programa segundo tempo. Texto para discussão. Rio de Janeiro: IPEA, 2009.

FUNDAÇÃO DE AMPARO À PESQUISA DO ESTADO DE SÃO PAULO. Recursos humanos disponíveis em ciência e tecnologia. In: INDICADORES FAPESP 8P (2005). Disponível em <http://www.fapesp.br/

indicadores2004/volume1/cap04_vol1.pdf>. Acesso em: Out. 2013.

GARCIA, J. C. R. Novas relações na transferência do conhecimento: patente, tecnologia, inovação. 2004. Tese (Doutorado em Ciência da Informação). Rio de Janeiro, 2004.

HAYASHI, M.C.P.I. et al. Indicadores de CT\&I no Pólo Tecnológico de São Carlos: primeiras aproximações. Revista Digital de Biblioteconomia e Ciência da Informação, Campinas, v. 3, n. 2, p. 17-30, jan. 2006;

HOLANDA, A. Biodiesel e Inclusão Social. Brasília: Câmara dos Deputados, Coordenação de Publicações, 2004.

INSTITUTO BRASILEIRO DE GEOGRAFIA E ESTATÍSTICA. Características do território nacional. Disponível em:

$<$ http://www.ibge.gov.br/home/geociencias/cartogramas/ctb.html>. Acesso em set. 2013. 
INSTITUTO BRASILEIRO DE GEOGRAFIA E ESTATÍSTICA. Divisão Regional. Disponível em <http://www.ibge.gov.br/home/

geociencias/geografia/default_div_int.shtm?c=1>. Acesso em set. 2013.

INSTITUTO DE ESTUDOS DE DESENVOLVIMENTO INDUSTRIAL. Incentivos para inovação: o que falta ao Brasil. ledi, 2010. Disponível em:

<http://www.iedi.org.br/admin_ori/pdf/20100211_inovacao.pdf>

KEIM, G. I.; Patente Americana US 2,383,601, 1945.

KNOTHE, G.; GESPEN, J. van; KRAHL, J. Manual de Biodiesel. São Paulo: Edgar Blucher, 2006.

LA VEGA, I. de Módulo de capacitación para la recolección y el análisis de indicadores de investigación y desarrollo. Publicações do Banco Interamericano de Desenvolvimento: Working Papers, Caracas, v. 6, n. 1, p.1-39, abr. 2010. Disponível em: http://docs.politicascti.net/documents/ Doc 06 - capacitacion de la vega.pdf>. Acesso em: 01 fev. 2014;

MARTINS, C. et al. O Processo de Inovação em um Instituto de Pesquisa \& Desenvolvimento: Caracterização e Análise. E-tech: Tecnologias para Competitividade Industrial, Florianópolis, v. 7, n. 2, p.24-50, jun. 2013;

MATTEI, L. F. Programa nacional para produção e uso do biodiesel no Brasil (PNPB): trajetória, situação e desafios. Florianópolis, 2007, p. 01. Disponível em <http://www.sober.org.br/palestra/9/79.pdf>. Acesso em: 10/06/2013;

MEULEMAN, M.; DE MASENEIRE, W. Do R\&D subsidies affect SMEs' access to external financing? Research Policy, n. 41, p. 580-591, 2012.

NUSSENZVEIG, M. Para que ciência no Brasil? Ciência e Tecnologia: Alicerces do Desenvolvimento. São Paulo: Cobram, 1994;

ORGANIZAÇÃO PARA COOPERAÇÃO E DESENVOLVIMENTO ECONÔMICO. Main definitions and conventions for the measuremant of research and experimental development (R\&D). A summary of the Frascati Manual (1994). Paris.

ORGANIZAÇÃO PARA COOPERAÇÃO E DESENVOLVIMENTO ECONÔMICO. Manual de Oslo: diretrizes para coleta e interpretação de dados sobre inovação. 2005. Disponível em: <www.mct.gov.br/index.php/ content/view/44912.html>. Acesso em out. 2013.

ORGANIZAÇÃO PARA COOPERAÇÃO E DESENVOLVIMENTO ECONÔMICO.. The OECD innovation strategy: innovation to strengthen growth and address global and social challenges. Paris: OCDE Publications, 2010.

PACHECO, E. M. Série Cartilhas Temáticas: Biodiesel. Ministério da Educação. Brasil. 2006.

PERUCCHI, V.; GARCIA, J. C. R. Indicadores de produção dos grupos de pesquisa do Instituto Federal de Educação, Ciência e Tecnologia da Paraíba. Revista 
Brasileira de Biblioteconomia e Documentação, São Paulo, v. 8, n. 1, p.50-64, jan. 2012;

PINTO, A. C. et al. Biodiesel: an Overview. J. Braz. Chem. Soc. [online]. 2005, v.16, n. 6 b, p. $1313-1330$.

PORTAL DO BIODIESEL - RBTB. Disponível em:

http://www.mme.gov.br/programas/biodiesel/menu/rede_brasileira_tecnologia/sobre_ a_rede. Acessoem: 14 ago.2013.

QUINTELLA et al. Cadeia do biodiesel da bancada à indústria: uma visão geral com prospecção de tarefas e oportunidades para P\&D\&I. Química Nova, São Paulo, v. 32, p. 793-808, 2009.

RAMOS, L.P.; WILHELM, H.M. Current status of biodiesel development in Brazil. Applied Biochemistry and Biotechnology, v. 121-124, p. 807-820, 2005.

RENEWABLE ENERGY POLICY NETWORK - REN21.Renewables 2013 Global Status Report. Paris: REN21 Secretariat, 2013. Disponível em: <www.ren21.net>. Acesso em: 15 jun. 2013.

ROCHA, A. M. et al. Indicadores Científicos e Tecnológicos em Biodiesel na Bahia. Revista Economia \& Tecnologia (RET), v.. 9, n. 3, p. 39-54, Jul/Set 2013.

ROCHA, E. M. P.; FERREIRA, M. A. T. Indicadores de ciência, tecnologia e inovação: mensuração dos sistemas de CT\&I nos estados brasileiros. Ciência da Informação, Brasília, v. 33, n. 3, p.61-68, set. 2004;

ROCHA NETO, I.; NEHME, C. Gestão do conhecimento, sistemas de inovação e complexidade. Parcerias Estratégicas- CGEE, Brasília-DF, v. 34, p. 65-86, 2012.

SCHUMPETER, J. A. The Theory of Economic Development. Tradução Brasileira Abril Cultural. São Paulo - SP, 1982

SILVA, Rafaela; MEDEIROS FILHO, Adonis Reis de; PIRES, Edilson Araújo. Análise da Evolução dos Indicadores de Produção Científica e de Produção Tecnológica na Universidade Federal de Sergipe. Anais Simtec, Aracaju/se, v. , n. 1, p.48-66, set. 2013

TEIXEIRA, F.C. O Desenvolvimento Brasileiro e a Formação do Sistema de Ciência e Tecnologia. In: A FINEP no Século XXI. Ed Finep, Rio de Janeiro - Rio de Janeiro, 2011.

WINTER, E. Fapesb sedia palestra sobre Indicadores Científicos, Tecnológicos e de Inovação no Brasil. Disponível em: <http://www.fapesb.ba.gov.br/?p=6510>. Acesso em set. 2013. 